\title{
CORRESPONDENCE
}

\section{Repair of Bland-White-Garland Syndrome via a Modified Technique}

\section{To the Editor:}

I read with interest the paper by Manoly and colleagues ${ }^{1}$ about their coronary extension technique, whereby they used a strip of pulmonary artery anteriorly and an aortic flap posteriorly in a 19-year-old woman who had Bland-White-Garland syndrome. Although our paper was not cited, my colleague and I had described this technique in 1992. We used it in a 21-month-old girl whose anomalous left coronary artery (LCA) arose from the anterior sinus of the pulmonary trunk. ${ }^{2}$ Because the patient's aortic defect was rather small, we did not patch it.

I want to report on the long-term outcome in our patient. An aortogram showed an unobstructed LCA when she was 5 years old. Catheterization data at that time showed no significant pressure gradient in the right ventricular outflow tract (right ventricular pressure, $40 / 6 \mathrm{mmHg}$; pulmonary artery pressure, 36/13 $\mathrm{mmHg}$ ). The patient is now 28 years old and is doing well, without symptoms or reoperation. This method, which we now call the double-flap method, produced good early and long-term results and is a useful adjunctive procedure for 2-coronary-system reconstruction when the LCA ostium is distant from the aorta.

Yutaka Imoto, $M D, P h D$,

Department of Cardiovascular and Gastrointestinal Surgery,

Kagoshima University Graduate School of Medical and Dental Sciences,

Kagoshima, Japan

\section{References}

1. Manoly I, Karangelis D, Viola N, Haw M. Repair of BlandWhite-Garland syndrome via a modified technique. Tex Heart Inst J 2014;41(1):48-50.

2. Sese A, Imoto Y. New technique in the transfer of an anomalously originated left coronary artery to the aorta. Ann Thorac Surg 1992;53(3):527-9.

http://dx.doi.org/10.14503/THIJ-15-5432

Letters to the Editor should be no longer than 2 double-spaced typewritten pages and should generally contain no more than 6 references. They should be signed, with the expectation that the letters will be published if appropriate. The right to edit all correspondence in accordance with Journal style is reserved by the editors. 